\title{
Anatomical Variations of Carotid Artery and Optic Nerve in Sphenoid Sinus Using Computerized Tomographic Imaging
}

\author{
Soheila Nikakhlagh ${ }^{1}$; Nader Saki ${ }^{1, *}$; Ghasem Saki ${ }^{2}$; Morteza Tahmasebi ${ }^{3}$; Mohammad \\ Davoodi $^{3}$; Fakher Rahim ${ }^{4}$ \\ ${ }^{1}$ Department of Otolaryngology, Faculty of Medicine, Jundishapur University of Medical Sciences, Ahvaz, IR Iran \\ 2 Department of Clinical Epidemiology, Faculty of Medicine, Jundishapur University of Medical Sciences, Ahvaz, IR Iran \\ 3 Department of Radiology, Faculty of Medicine, Jundishapur University of Medical Sciences, Ahvaz, IR Iran \\ ${ }^{4}$ Department of Anatomy, Faculty of Medicine, Jundishapur University of Medical Sciences, Ahvaz, IR Iran \\ ${ }^{*}$ Corresponding author: Nader Saki, Department of Otolaryngology, Faculty of Medicine, Jundishapur University of Medical Sciences, Ahvaz, IR Iran. Tel: +98-6133738383, \\ E-mail:sakin@yahoo.com
}

Received: July 4, 2014; Revised: September 10, 2014; Accepted: October 22, 2014

\begin{abstract}
Background: Sphenoid sinus is surrounded by many vital vascular and nervous structures. In more than $20 \%$ of patients with chronic sinusitis, involvement of sphenoid sinus has been observed. Besides, sphenoid sinus is an appropriate route to access anterior and middle cranial fossa in surgery. Therefore, it is important to have an adequate knowledge about the contents of sphenoid sinus and its proximity for nasal endoscopy, sinus surgeries and neurosurgeries.

Objectives: The aim of this study was to study sphenoid sinus proximity with carotid artery and the optic nerve using computerized tomographic imaging.

Materials and Methods: In this prospective study, computerized tomographic images of sphenoid sinus of patients referred to Imam Khomeini and Apadana hospitals were studied. The images were studied regarding any bulging, as well as not having a bone covering in sphenoid sinus regarding internal carotid artery and optic nerve. Furthermore, unilateralness or bilateralness of their relationships was studied.

Results: Among 468 coronal and axial CT scan images of sphenoid sinus, 365 (78\%) showed post-sellar pneumatization and 103 (22\%) presellar pneumatization. Regarding existence of internal septa, 346 (74\%) cases showed multiple septation, and the remaining images were reported to have a single septum. According to the reports of CT scan images, the existence of bulging as a result of internal carotid artery and uncovered artery were $4.22 \%$ and $5.8 \%$ in the right sinus, $4.9 \%$ and $5.4 \%$ in the left sinus, and $4.34 \%$ and $4.6 \%$ in both sinuses, respectively. According to the reports of CT scan images, existence of bulging as a result of optic nerve and uncovered nerve were $5.7 \%$ and $4.3 \%$ in the right sinus, $6 \%$ and $5.4 \%$ in the left sinus, and $12 \%$ and $3.2 \%$ in both sinuses, respectively.

Conclusions: Due to variability of sphenoid sinus pneumatization and the separator blade of the two sinus cavities, careful attention is required during sinus surgery to avoid damage to neural and vascular structures in its proximity.
\end{abstract}

Keywords:Sphenoid Sinus; Carotid Artery, Internal; Optic Nerve

\section{Background}

Sphenoid sinus is the most unaccessible paranasal sinus. It is surrounded by sphenoid bone and there are a lot of neural and vascular structures in its proximity. Sphenoid bone is in skull base and involved in forming anterior and middle cranial fossa. This bone comprises a body, greater wings, lesser wings and pterygoid (1). In the thick part of the body, there is a cavity full of air. It is separated into right and left halves by a bone septum. Each half is directed into the nasal cavity through an opening located in the interior part of the superior turbinate (2). Sinus pneumatization is considerably varied in different people. The walls of sinuses are covered by mucosal tissue. Its glands secrete mucoid, which is emptied into the nose through special ducts (3). There are many vital vascular and nervous structures near the sphenoid including internal carotid artery, which plays an important role in supplying the brain and eyes. From intracranial view, it passes through greater wings joint to the body. Internal carotid artery is so close to the body and forms a track on it called carotid (4). Optic nerve is close to the body of the bone and passes between two roots related to lesser wings and attached to the body from a lateral view. An artery called ophthalmic artery passes beside the optic nerve (5).

Studies showed that the internal carotid artery and optic nerve routes would change based on sphenoid sinus pneumatization, which are observed as bulging on the sidewall of the sinus. It is also possible to observe artery and nerve without bone covering in sinus wall $(4,6)$. Involvement of sphenoid sinus has been observed in more than $20 \%$ of patients with chronic sinusitis, besides sphenoid sinus is an appropriate route to access anterior and middle cranial fossa in surgery (e.g. pituitary gland surgery). Therefore, it is important to have adequate knowl-

Copyright (C) 2014, Ahvaz Jundishapur University of Medical Sciences. This is an open-access article distributed under the terms of the Creative Commons Attribution-NonCommercial 4.0 International License (http://creativecommons.org/licenses/by-nc/4.0/) which permits copy and redistribute the material just in noncommercial usages, provided the original work is properly cited. 
edge of the contents of sphenoid sinus and its proximity in nasal endoscopy, sinus surgeries and neurosurgeries.

\section{Objectives}

Since there is lack of knowledge regarding carotid artery variations with sphenoid sinus in Iranian cases, we aimed to study sphenoid sinus proximity with internal carotid artery and the optic nerve using computerized tomographic imaging as a precise tool in paranasal sinuses.

\section{Materials and Methods}

In this prospective study, 468 coronal and axial CT scan images of sphenoid sinuses of patients referred to Imam Khomeini and Apadana hospitals during 2003-2009 were assessed by a radiologist, an ENT (ear, nose, and throat) specialist and an anatomist. CT scan machine used in this study was spiral 16 slice. The images were checked to have lumps in internal carotid artery and optic nerve, also unilateralness or bilateralness of their relationship was studied. They were also checked for having bone covering in internal carotid artery and optic nerve, unilaterally and bilaterally in sphenoid sinus. Exclusion criteria in this study were patients with damaged sphenoid sinus, patients with an earlier record of sphenoid surgery and patients younger than 12 years. Studying sphenoid sinus in patients younger than 12 years is complicated due to underdevelopment of sphenoid sinus. Hence, they were excluded from the study (7). Patients personal information including their age was collected at the time of examination. Information regarding age was only useful to determine whether the patient was older or younger than 12 years. Bulging, internal carotid artery and optic nerve in the sinus, as well as patient's age, and involved side were the study variables. If the internal carotid artery or the optic nerve had formed a bony bulging, it was categorized as bulging, and if the bulging had no bony covering, it was categorized as existence of artery or nerve in the sinus.

\section{Results}

In this prospective study, $468 \mathrm{CT}$ coronal scan images of sphenoid sinus were studied. The images were checked for having bulging in internal carotid artery or optic nerve, and unilateralness or bilateralness of their relationships. Among all studied scans, 365 cases (78\%) showed post-sellar pneumatization and 103 (22\%) presellar pneumatization. Regarding the existence of internal septa, 346 cases (74\%) were reported to have multiple septation and the remaining cases had a single septum. The existence of bulging as a consequence of internal carotid artery and uncovered artery were reported to be $4.22 \%$, and $5.8 \%$ in the right sinus, $4.9 \%$, and $5.4 \%$ in the left sinus and $4.34 \%$ and $4.6 \%$ in both sinuses, respectively (Figures 1, 2 and 4). The existence of bulging due to optic nerve and uncovered nerve were reported to be $5.7 \%$ and $4.3 \%$ in the right sinus, $6 \%$ and $5.4 \%$ in the left sinus and $12 \%$ and $3.2 \%$ in both sinuses, respectively (Table 1) (Figure 3). In 3.36\% of scans, vidian nerve was seen as a bulging under sphenoid sinus (Figure 2).
Table 1. Anatomical Variations of the Internal Carotid Artery and the Optic Nerve in Sphenoid Sinus Using Computerized Tomographic Scans ${ }^{\text {a }}$

\begin{tabular}{lllll}
$\begin{array}{l}\text { Variables under } \\
\text { investigation }\end{array}$ & Right Sinus & Left Sinus & Bilateral & Total \\
\hline $\begin{array}{l}\text { Lump in internal } \\
\text { carotid artery }\end{array}$ & $105(4.22)$ & $44(4.9)$ & $161(4.34)$ & $310(2.66)$ \\
$\begin{array}{l}\text { Lump in the optic } \\
\text { nerve }\end{array}$ & $35(5.7)$ & $28(6)$ & $56(12)$ & $119(5.25)$ \\
$\begin{array}{l}\text { Existence of } \\
\text { artery in sinus }\end{array}$ & $40(5.8)$ & $21(5.4)$ & $30(4.6)$ & $91(4.19)$ \\
$\begin{array}{l}\text { Existence of optic } \\
\text { nerve in sinus }\end{array}$ & $16(4.3)$ & $21(5.4)$ & $11(3.2)$ & $49(5.10)$ \\
\hline
\end{tabular}

${ }^{\mathrm{a}}$ Data are presented as No. (\%).

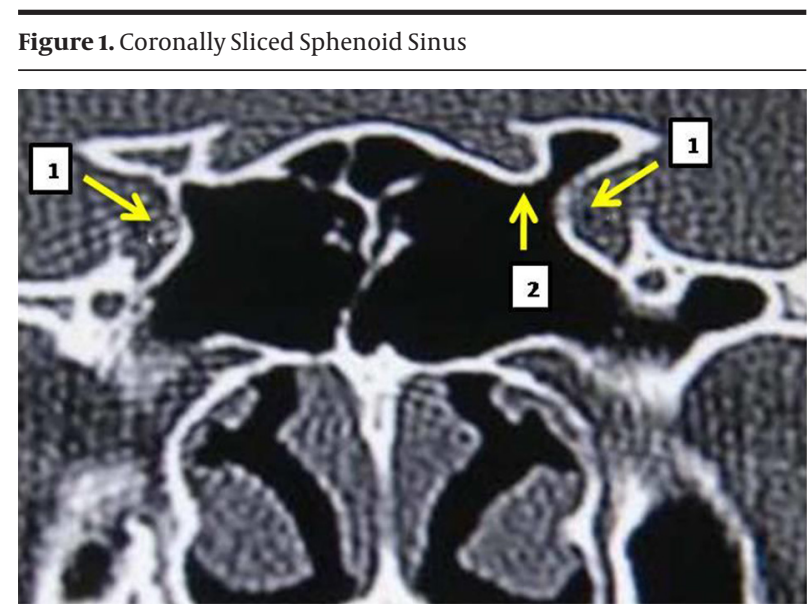

1. bulging of the internal carotid artery, 2. Bulging of the left optic nerve.

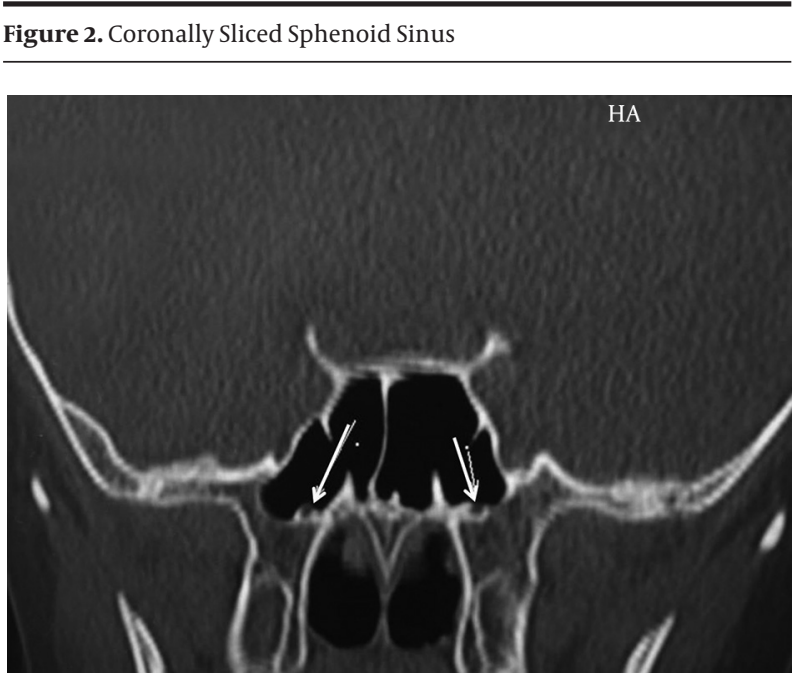

Naked, and bulged vidian canal is marked by an arrow. 
Figure 3. Axially Sliced Sphenoid Sinus

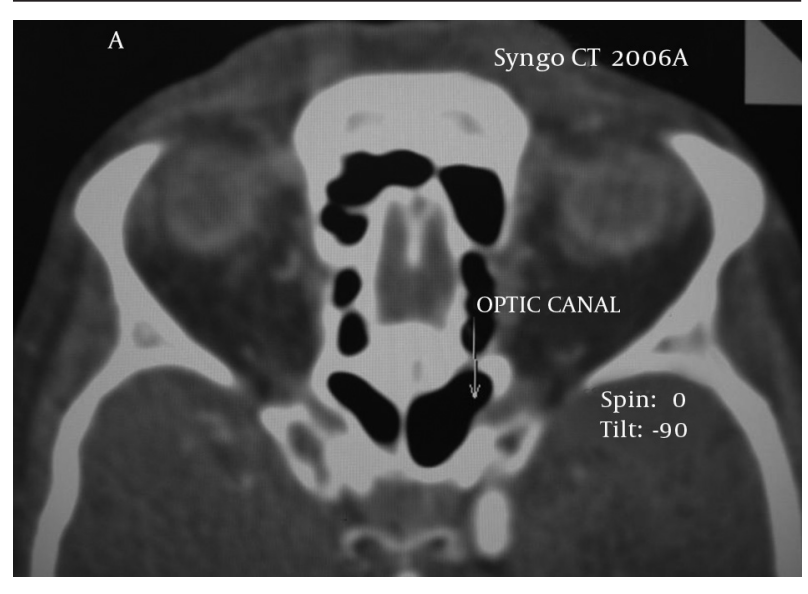

Naked and bulged optic nerve is marked by an arrow.

Figure 4. Coronally Sliced Sphenoid Sinus

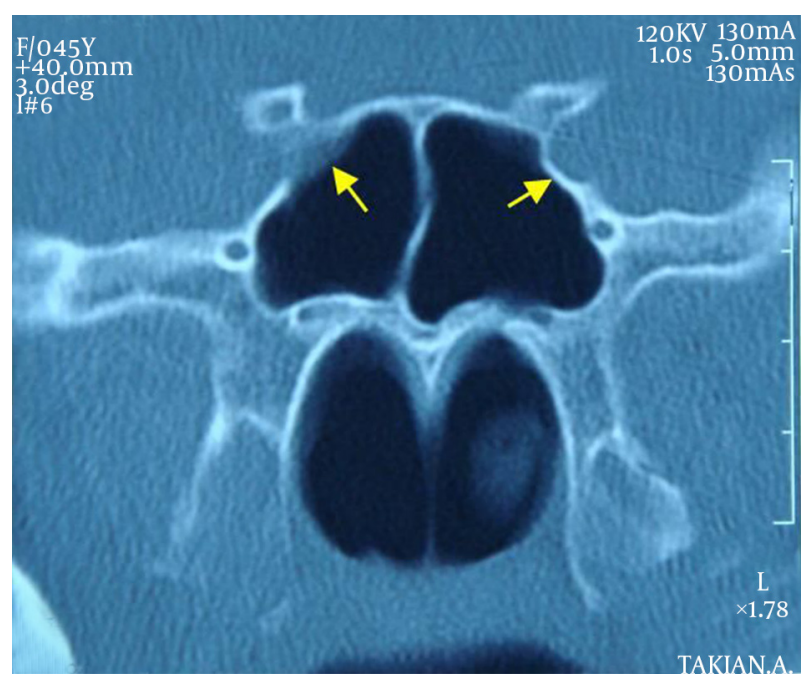

Internal carotid artery bulging (left), uncovered carotid artery (right).

\section{Discussion}

There are few researches performed on sphenoid sinus and its proximity with internal carotid artery and optic nerve. In a study by Unal, et al. 59 tomographic scans of Turkish patients were studied. According to that study, in $3.30 \%$ of patients the internal carotid artery, in $3.31 \%$ of the cases the optic nerve, and in 3.35\% the vidian nerve was observed as a bulging (8) (Figure 2). In the mentioned study, there was no assessment of unilateralness or bilateralness of the bulging in the sphenoid sinus. There was no mention of the existence of artery in uncovered sphenoid sinus cavity. In the current study, 468 coronal CT scan images of sphenoid sinus were checked for existence of bulging in sphenoid sinus and uncovered internal carotid artery or optic nerve. Moreover, unilateralness or bilateralness of the relationship between them was studied.Among the studied scans, 365 cases (78\%) showed post-sellar pneumatization and 103 (22\%) pre-sellar pneumatization. Regarding the existence of internal septa, 346 cases (74\%) had multiple septation, while the remaining cases had a single septum. Bulging in sphenoid sinus because of internal carotid artery and uncovered artery in the scans were reported to be $4.22 \%$, and $5.8 \%$ in the right sinus, $4.9 \%$, and $5.4 \%$ in the left sinus and $4.34 \%$ and $4.6 \%$ in both sinuses, respectively. The existence of bulging in sphenoid sinus due to optic nerve and uncovered nerve in the scans were reported to be $5.7 \%$ and $4.3 \%$ in the right sinus, $6 \%$ and $5.4 \%$ in the left sinus, and $12 \%$ and $3.2 \%$ in both sinuses, respectively. Mentioned figures are lower compared to global outbreak. Kantarci et al. studied 90 tomographic scans of patients (9). Among all cases, 16\% had bilateral and 7\% unilateral internal carotid lump. According to another study performed by Nikakhlagh et al. on 290 patients, $28 \%$ of cases had bulging in the sphenoid sinus (10). There was no mention of anatomical location of the internal carotid artery in their study. Dessi et al. in a prospective study studied computerized tomographic scans of 150 patients. They found that in $8 \%$ of patients, the optic nerve had a bulging in sphenoid sinus. It was also discovered that the optic nerve did not have a bulging in posterior ethmoid sinus in any of the observed cases. In their research, the optic nerve was studied only and there was no mention of either internal carotid artery or its proximity with sphenoid sinus $(11,12)$.

In conclusion due to variability of sphenoid sinus pneumatization and the separator blade of the two sinus cavities, careful attention is required during sinus surgery to avoid damage to neural and vascular structures in its proximity. A surgeon must be especially careful during operation on a carotid artery or optic nerve that does not have any bony covering to avoid possible damage to these structures. The superior turbinate is a reliable indicator for locating sphenoid sinus, especially in further surgeries, since the middle turbinate is taken out in the first operation.

\section{Acknowledgements}

The current study was related to a research project (U88344 ) passed by the vice chancellor of research, Ahvaz Jundishapur University of Medical Sciences. The authors would like to thank the vice chancellor of research and technology of university for financing our study.

\section{Authors' Contributions}

All authors had equal role in design, work, statistical analysis and manuscript writing.

\section{Funding/Support}

Ahvaz Jundishapur University of Medical Sciences has been supported this study. 


\section{References}

1. Gray H. Gray's anatomy. 37th edEdinburgh: Churchill Livingstone; 2008.

2. Davoodi M, Saki N, Saki G, Rahim F. Anatomical variations of neurovascular structures adjacent sphenoid sinus by using CT scan. PakJ Biol Sci. 2009;12(6):522-5.

3. Saki N, Nikakhlagh S, Rahim F. Sphenochoanal polyps.J Coll Physicians Surg Pak. 2010;20(5):353-4.

4. Cheung DK, Attia EL, Kirkpatrick DA, Marcarian B, Wright B. An anatomic and CT scan study of the lateral wall of the sphenoid sinus as related to the transnasal transethmoid endoscopic approach.J Otolaryngol. 1993;22(2):63-8.

5. Saki N, Nikakhlagh S, Rahim F. J Coll Physicians Surg Pak.Tehran: Nashreh Ashora; 2010.

6. Mafee MF, Chow JM, Meyers R. Functional endoscopic sinus surgery: anatomy, CT screening, indications, and complications. AJR Am J Roentgenol. 1993;160(4):735-44.

7. Chen YL, Lee LA, Lim KE. Surgical consideration to optic nerve

protrusion according to sinus computed tomography. Otolaryngol Head Neck Surg. 2006;134(3):499-505.

8. Unal B, Bademci G, Bilgili YK, Batay F, Avci E. Risky anatomic variations of sphenoid sinus for surgery. Surg Radiol Anat. 2006;28(2):195-201.

9. Kantarci M, Karasen RM, Alper F, Onbas O, Okur A, Karaman A Remarkable anatomic variations in paranasal sinus region and their clinical importance. EurJ Radiol. 2004;50(3):296-302.

10. Nikakhlagh S, Rahim F, Saki N, Mohammadi H, Maliheh YM. Antrochoanal polyps: report of 94 cases and review the literature. Niger J Med. 2012;21(2):156-9.

11. Dessi P, Moulin G, Castro F, Chagnaud C, Cannoni M. Protrusion of the optic nerve into the ethmoid and sphenoid sinus: prospective study of 150 CT studies. Neuroradiology. 1994;36(7):515-6.

12. Nikakhlagh S, Saki N, Tahmasebi M, Johari H. Anatomic variations of the bone in sinonasal CT Scan. Jundishapur Sci Med J. 2008;6(4):476-82. 